\title{
La conformación intersubjetiva de la libertad: un análisis de la influencia de Fichte en la filosofía de Kierkegaard
}

\author{
The intersubjective conformation of freedom: an analysis of \\ Fichte's influence on Kierkegaard's philosophy
}

\begin{abstract}
Pablo Uriel Rodríguez*
Resumen: El pensamiento de Kierkegaard fue fuertemente influenciado por los filósofos idealistas alemanes. Mientras que los especialistas estudiaron el vínculo filosófico entre Hegel (o Schelling) y el danés, la relación de Kierkegaard con Fichte permaneció en silencio. El propósito de este artículo es desarrollar una nueva perspectiva de la relación Fichte-Kierkegaard. Primero, exploramos las lecturas que Kierkegaard realizó sobre el sistema de Fichte. Segundo, discutimos las nuevas interpretaciones globales de la filosofía kierkegaardeana y el puesto que en ellas ocupa Fichte. Tercero, mostramos que el concepto fichteano de Aufforderung está a la base de la teoría del yo expuesta por Kierkegaard en sus últimos libros.
\end{abstract}

Palabras clave: Kierkegaard, Fichte, intersubjetividad, yo, libertad

Abstract: Kierkegaard's thought was strongly influenced by German idealist philosophers. While the scholars have studied the philosophical link between Hegel (or Schelling) and the danish, Kierkegaard's relation with Fichte remained silent. The purpose of this article is to develop a new perspective on the FichteKierkegaard relationship. First, we explore Kierkegaard's readings on Fichte's system. Second, we discuss the new global interpretations of Kierkegaard's philosophy and the place of Fichte in these interpretations. Third we show that

${ }^{*}$ Doctor en Filosofía por la Universidad de Morón y Profesor en Filosofía por la Universidad de Buenos Aires. Becario Postdoctoral del CONICET, Argentina. Docente Adscripto de "Filosofía Social y Teoría Política" en la UM. Es integrante del equipo docente del Programa de Postgrado de Actualización en Problemas Filosóficos de la UBA (Filosofía Contemporánea) y Secretario de Coordinación del Programa de Investigación en Filosofía Posthegeliana del Instituto de Ciencias de la Universidad Nacional de General Sarmiento. Dirección electrónica: blirius@hotmaiil.com 
Fichte's concept of Aufforderung is on the ground of the self's theory that Kierkegaard exposes in his latest books.

Keywords: Kierkegaard, Fichte, intersubjectivity, self, freedom

A principios de la década de 1960, Paul Ricoeur señaló que quienes se propusieran filosofar desde Kierkegaard ${ }^{1}$ debían hacerlo reconsiderando su relación con el Idealismo Alemán. Esta pauta de trabajo compromete al lector contemporáneo del danés con tres tareas estrechamente relacionadas: i) la de re-examinar la polémica anti-hegeliana que nutre los diversos textos kierkegaardeanos sin partidismos y en su justa medida; ii) la de visualizar el impacto de Kant, Fichte y Schelling en el origen y la evolución del itinerario intelectual del danés y iii) la de releer la obra de los antecesores alemanes de Kierkegaard abandonando la interpretación oficial de una evolución

${ }^{1}$ Para las citas de Kierkegaard utilizamos la última edición de sus obras completas indicando en números arábigos tanto el volumen como la página: Soren Kierkegaard Skrifter (SKS), (ed.) N. J Cappelørn, J. Garff, J. Kondrup, A. McKinnon y F. H. Mortensen, Copenhague, Søren Kierkegaard Forskningscenteret y Gads Forlag, 1997 - 2009 (55 volúmenes entre textos y comentarios). Ofrecemos, también, la paginación correspondiente de las siguientes traducciones al castellano: Los primeros diarios. Volumen 1: 1834-1837, trad. Binetti, Méjico, Universidad Iberoamericana, 2011 [D]; Escritos de Soren Kierkegaard. Volumen 1. Sobre el concepto de ironía, trad. González, Madrid, Trotta, 2000 [CI]; Escritos de Søren Kierkegaard. Volumen 2/1. O lo uno o lo otro. Un fragmento de vida I, trad. González y Tajafuerce, Madrid, Trotta, 2006 [OO I]; Jobannes Climacus, o De todo hay que dudar, trad. Lafuente, Barcelona, Alba, 2008 [JC]; Escritos de Søren Kierkegaard. Volumen 4/2. Migajas Filosóficas o un poco de Filosofia. El concepto de la angustia, trad. Gonzáles y Parcero, Madrid, Trotta, 2016 $[\mathrm{MF}]$ - [CA]; Postscriptum no cientifico y definitivo a Migajas Filosóficas, trad. Bravo Jordán, Méjico, Universidad Iberoamericana, 2008 [PC]; La enfermedad mortal, trad. Rivero, Madrid, Sarpe, 1984 [EM]; Las obras del amor. Tomo I y II, trad. Rivero, Madrid, Guadarrama, 1965 [LOA I - II] y Ejercitación del cristianismo, trad. Rivero, Madrid, Guadarrama, 1961 [EC]. 
filosófica de Kant a Hegel. ${ }^{2}$ Un repaso por algunos de los últimos intentos de acercamiento a la obra de Kierkegaard permite constatar que el proyecto de investigación esbozado por Ricoeur comenzó a ser puesto en práctica de forma incipiente. La meta principal de esta comunicación es la de marcar y, de ser posible, comenzar a corregir algunos de los déficits presentes en las actuales tentativas teóricas dedicadas al estudio de la relación entre Kierkegaard y el Idealismo Alemán. Con este objetivo en mente, me propongo el análisis del caso testigo de Fichte. ${ }^{3}$ Tres motivos justifican esta elección. La primera razón es que, al día de la fecha y hasta donde llegan nuestros conocimientos sobre el tema, no existe en castellano ningún trabajo que interrogue específicamente cuál fue el significado de la filosofía de Fichte para el pensamiento del danés. ${ }^{4}$ La segunda razón, en sintonía con

${ }^{2}$ Véase Ricoeur, Paul, "Philosophieren nach Kierkegaard", Theunissen, Michael \& Greve, Wilfried (ed.), Materialien zur Pbilosophie Soren Kierkegaards, Frankfurt am Main, Suhrkamp, 1979, pp. 579 - 596.

${ }^{3}$ Para las citas de Fichte utilizamos la edición de la Academia de Baviera de sus obras completas indicando en números romanos la serie, en números arábigos el tomo y la correspondiente paginación: Fichte, J. G., Gesamtausgabe der Bayerischen Akademie der Wissenchaften (GA), (ed.) Lauth R. et alia, Stuttgart/Bad Cannstatt, Frommann-Holzboog, 1962 y ss. A su vez, ofrecemos la paginación correspondiente de las siguientes traducciones al castellano: Fundamento de Toda la Doctrina de la Ciencia, trad. Cruz Cruz, Buenos Aires, Aguilar, 1975 [FDC]; Primera y Segunda Introducción Doctrina de la Ciencia nova methodo, trad. Acosta y Rosales, Madrid, Ediciones Xorki, 2016 [IntroDC]; Fundamentos del Derecho Natural. Según los principios de la Doctrina de la Ciencia, trad. Villacañas J., Ramos Valera M. y Oncina F., Madrid, Centro de Estudios Constitucionales, 1994 [FDN], Sobre la capacidad lingüística y el origen de la lengua, trad. Radl Philipp, Tecnos, Madrid, 1996 [OL]. Ética o El sistema de la doctrina de las costumbres según los principios de la Doctrina de la Ciencia, trad. Rivera Rosales, Madrid, Akal, 2005 [E].

${ }^{4} \mathrm{El}$ reciente libro de la especialista argentina María José Binetti tiene como uno de sus ejes centrales una reconsideración de la relación entre Kierkegaard y la filosofía alemana post-kantiana (romanticismo, idealismo y posthegelianismo). La autora se concentra más que nada en la influencia y la polémica con Hegel, Schelling, los románticos y el posthegelianismo; la figura de Fichte, sin embargo, recibe poca atención (véase Binetti, María José, El idealismo de Kierkegaard, Méjico, Universidad Iberoamericana, 2016). José Luis Vermal en un artículo de 1987 dedicado a La 
la propuesta de Ricoeur y a contracorriente de la gran mayoría de las investigaciones precedentes, consiste en la necesidad de revisar la relación Fichte- Kierkegaard más allá de los límites trazados por la comprensión hegeliana de la Doctrina de la Ciencia a la cual el danés adhiere en un nivel consciente. La tercera y última razón es la de ofrecer una nueva lectura de la propuesta filosófica del danés a partir de un reenfoque de la cuestión Fichte- Kierkegaard que permanezca atento a ciertas afinidades teóricas entre ambos autores que la actual literatura especializada pasa por alto, en la casi totalidad de sus casos.

El trabajo consta de tres partes. La primera de ellas ofrece un breve repaso de la lectura que Kierkegaard hace de la obra de Fichte. La segunda ofrece un relevamiento crítico del modo en que se piensa la cuestión FichteKierkegaard en el marco de las más recientes interpretaciones del pensamiento del danés. La tercera propone un nuevo acercamiento a la relación entre la filosofía fichteana y la kierkegaardeana a la luz del concepto de intersubjetividad.

\section{i. La recepción kierkegaardeana de Fichte}

Las menciones a Fichte en el conjunto de las obras publicadas por Kierkegaard son más bien escasas y de carácter fragmentario. Como hilo conductor del breve análisis de estas referencias proponemos la siguiente clave de lectura: el tratamiento que Fichte recibe por parte del danés está atado a los vaivenes del vínculo entre este último y la filosofía hegeliana. Jon Stewart ha identificado tres momentos en la relación hegelianismoKierkegaard: 1) un primer período de influencia positiva que va desde 1834 hasta 1843,2) un período intermedio signado por la polémica entre $1843 \mathrm{y}$ 1847 y 3) un período final, a partir del año 1847, donde algunos aspectos del pensamiento hegeliano son incorporados pero prima cierta

enfermedad mortal presenta algunas breves, pero interesantes, consideraciones en torno a la relación de Kierkegaard con Fichte (Vermal, José Luis, "La crítica de la concepción idealista del sujeto en La enfermedad mortal de S. Kierkegaard" en Taula. Quaderns de Pensament, No 7-8, (1987), pp. 205-212). 
indiferencia. ${ }^{5}$ De forma correspondiente podemos decir que: 1) hasta 1843 Kierkegaard adhiere a la recepción hegeliana del pensamiento fichteano, 2) entre 1844 y 1846 el danés considera a Fichte como un exponente de esa filosofía científica que encuentra en Hegel su máxima expresión y a la cual dirige sus críticas y, por último, 3) a partir de 1847 hay una reconsideración y apropiación de ciertos elementos de la filosofía fichteana.

En marzo de 1835 Kierkegaard adquiere un ejemplar de Die Bestimmung des Menschen (El destino del hombre, 1800) de Fichte. Meses después, el 29 de julio de ese mismo año, vuelca en su Diario personal la primera referencia al filósofo alemán. ${ }^{6}$ El libro de Fichte llegó a sus manos en una etapa especial de su trayecto vital e intelectual; por ese entonces, el joven estudiante universitario, prometedor, pero muy disperso, atraviesa una crisis de identidad que lo lleva a pasar algunas semanas alejado del trajín de Copenhague en Gilleleje. Kierkegaard estaba en la búsqueda de un polo orientador para su conducta, quería descubrir su auténtico destino y encontrar una idea a la cual consagrar todos sus esfuerzos. ${ }^{7}$ Resulta prácticamente imposible precisar si el escrito de Fichte lo ayudó a contestar alguno de sus interrogantes, lo que sí es cierto es que sus notas íntimas dejan traslucir el profundo impacto producido por su lectura: en las reflexiones personales del joven danés resuena el eco de dos de los principales motivos de El destino del hombre; en primer lugar, la tesis de la primacía de la acción práctica (voluntad) por sobre el conocimiento contemplativo (entendimiento) y, en segundo lugar, el reconocimiento del carácter libre (no natural) de la esencia del hombre. ${ }^{8}$

5 Véase Stewart, Jon, Kierkegaard's Relation to Hegel Reconsidered, New York, Cambridge University Press, 2003, pp. 597-615.

${ }^{6}$ Véase SKS 17: 15 / D: 71.

${ }^{7}$ Véase SKS 17: 24 / D: 80.

8 Véase Kangas, David, “J. G. Fichte: From Transcendental Ego to Existence" en Stewart, Jon (ed.), Kierkegaard and his German Contemporaries. Tome I: Philosophy, Aldershot, Ashgate, 2007, p. 70. Schmidinger, por su parte, sostiene una posición cercana a Kangas (véase Schmidinger, Heinrich, "Kierkegaard und Fichte", en Gregorianum, vol. 62, (1981), pp. 515-517). 
El tratamiento más extenso del pensamiento fichteano aparece en la Segunda Parte de la tesis Om Begrebet Ironi (Sobre el concepto de ironía, 1841). La exposición del danés se limita al primer Fichte, es decir, al sistema filosófico de los Grundlage der gesamten Wissenchaftslehre (Fundamentos de toda la Doctrina de la Ciencia) de 1794. ${ }^{2}$ La primera mención se encuentra en la "Introducción" de la Segunda Parte, allí el pensamiento de Fichte se presenta como la culminación de aquella nueva etapa de la filosofía moderna abierta con Kant cuya característica fundamental es la acentuación del principio subjetivo, "una segunda potencia de la subjetividad, una subjetividad de la subjetividad correspondiente a una reflexión de la reflexión". ${ }^{10}$ Pocas páginas después de esta escueta referencia inicial, el danés vuelve a ocuparse de Fichte en una sección titulada "La ironía después de Fichte". El apartado en cuestión opera como una suerte de introducción al tema principal de la segunda parte de su tesis, a saber, la exposición y el análisis crítico de la ironía romántica. Siguiendo las Lecciones sobre Estética de Hegel, Kierkegaard considera que el romanticismo es un resultado del sistema filosófico fichteano; sin embargo, al igual que Hegel, sostiene que los pensadores y artistas románticos asumen una orientación que no estaba presente en su fuente. Pese a todos sus esfuerzos, la filosofía kantiana terminó chocando con algo ajeno e irreductible a la experiencia, "ese algo exterior, esa Ding an sich fue la debilidad del sistema kantiano". ${ }^{11} \mathrm{El}$ sistema fichteano surgirá con el propósito de solucionar el problema de la "cosa en sí", como un intento de barrer con los restos de dogmatismo ${ }^{12}$ aún presentes en Kant: "Fichte se deshizo de la dificultad de este an sich colocándolo dentro del pensamiento, infinitizando el Yo en el Yo-Yo. El Yo productor es el mismo que el Yo

\footnotetext{
${ }^{9}$ Véase SKS 1: 310 / CI: 298.

10 SKS 1: 282 / CI: 272.

11 SKS 1: 309 / CI: 296.

${ }^{12}$ No empleamos el término en el sentido kantiano, sino en el sentido definido por Fichte en Fundamento de toda Doctrina de la Ciencia de 1794: "una filosofía que pone algo idéntico y opuesto al Yo en sí es dogmática; y esto ocurre en el seno del concepto, pretendidamente superior, de cosa $(E n s)$... En el sistema crítico la cosa es aquello que es puesto en el Yo; en el sistema dogmático, es aquello que en el mismo Yo es puesto..." (GA I, 2: 279 / FDC: 32).
} 
producido"13. ¿En qué sentido este paso fichteano más allá del criticismo kantiano es el origen teórico de la ironía romántica? La filosofía fichteana profundizó el giro subjetivo kantiano postulando al Yo como único punto de partida de la filosofía, en palabras del propio Fichte, como principio "absoluto, completamente incondicionado y no determinable por algo más elevado".14 Con Fichte, continúa argumentando Kierkegaard, el Yo adquiere valor constitutivo, pero, de este modo, el objeto, la realidad, perdió esa densidad ontológica que todavía conservaba con Kant. ${ }^{15}$ Como apunta Hegel en su Estética, a partir del primado del Yo los románticos concluyeron que el mundo "es sólo una apariencia, no verdadero y efectivamente real por sí mismo y a través de sí mismo, sino un mero aparecer a través del yo, a la libre disposición de cuyo poder y arbitrio permanece". ${ }^{16}$ La subjetividad romántica, escribe en sintonía Kierkegaard, "se presentaba entonces como aquella ante la cual nada subsistía y que, habiendo roto con todo, tenía además pleno poder para hacer cualquier cosa. Si dejaba que algo subsistiese, sabía que tenía el poder de anularlo, y esto lo sabía en el mismo instante en que lo dejaba subsistir". ${ }^{17}$ Resulta necesario, sin embargo, distinguir con claridad entre la posición de Fichte y sus derivaciones románticas (Schlegel, Tieck y Solger). ${ }^{18}$ El primer problema de la apropiación romántica de Fichte consiste en borrar una distinción fundamental del sistema fichteano: en el romanticismo "el Yo empírico y

\footnotetext{
${ }^{13}$ SKS 1: 309 / CI: 296.

${ }^{14}$ GA I, 2: 279 /FDC: 32.

15 Véase SKS 1: 309 / CI: 296.

${ }^{16}$ Hegel, George, Lecciones sobre la Estética, trad. Brotóns Muñoz, Madrid, Akal, 1989, p. 50 .

${ }^{17}$ SKS 1: 312 / CI: 298.

18 Para un análisis pormenorizado y de carácter crítico de la visión que ofrece Kierkegaard del romanticismo puede consultarse Behler, Ernst, "Kierkegaard's the Concept of Irony with Constant Reference to Romanticism" en Cappelørn, Niels J. \& Stewart, Jon (ed.), Kierkegaard Revisited. Proceedings from the Conference Kierkegaard and the Meaning of Meaning It, Berlin/New York, Walter de Gruyter Verlag, 1997, pp. 13-33.
} 
finito se confundía con el Yo eterno". ${ }^{19}$ Dicho de otro modo, de acuerdo con Kierkegaard, los románticos pasan por alto que el Yo de la Doctrina de la Ciencia no hace referencia a una subjetividad individual (tampoco a un macro-sujeto), sino a una instancia originaria interna a y constitutiva de toda conciencia. $^{20}$ La segunda dificultad radica en un desplazamiento: el romanticismo "aplicaba sin más a la realidad una prematura posición metafísica ${ }^{21}$. Fichte quería construir el mundo [vilde construere Verden], pero con ello se refería a una construcción sistemática [systematisk Construeren]. Schlegel y Tieck querían instaurar un mundo [vilde skaffe en Verden tilvere]". ${ }^{22}$ Lo que Kierkegaard quiere dejar en claro es que el Yo del cual habla Fichte, a diferencia del Yo de los románticos, no debe pensarse como un "creador" del mundo. "Construir sistemáticamente el mundo" significa deducir la experiencia únicamente desde la libre actividad del Yo, es decir, derivar desde el principio subjetivo el conjunto organizado y relacionado de todas las representaciones que permiten conocer la realidad. ${ }^{23}$

${ }_{19}$ SKS 1: 311 / CI: 298. Fichte distingue claramente esta cuestión: "Pudiera ser que tú hayas recogido en el concepto de Yo algunas cosas que yo no he recogido en él, por ejemplo, el concepto de tu individualidad, porque también éste es designado con ese signo lingüístico. De todo esto se te dispensa de aquí en adelante; únicamente aquello que se forma mediante el retorno de tu pensar sobre sí mismo es el Yo del cual hablo aquí" (GA I, 4:273 /IntroDC: 139).

${ }^{20}$ Véase Zöller, Günter, Leer a Fichte, trad. Rivero, Barcelona, Herder, 2015, p. 46. 21 "Hegel le reprocha a Fr. Schlegel haber arrancado de su contexto metafísico, por imprudencia y por despecho hacia lo especulativo, el principio fichteano acerca del valor constituyente del Yo, haberla arrancado del ámbito del pensamiento y aplicado directamente a la realidad..." (SKS 1: 305 / CI: 293).

22 SKS 1: 311 / CI: 298.

${ }^{23}$ Burns afirma que en Sobre el concepto de la ironía el pensamiento de Fichte es acusado de "idealismo", pero que si se analiza la exposición con rigurosidad resulta notorio que la posición fichteana es rechazada en la medida en que se la interpreta como un "idealismo subjetivo" (véase O’Neill Burns, Michael, Kierkegaard and the matter of Philosophy. A fractured dialectic, London/New York, Rowman \& Littlefield, 2015, p. 34). Para ser más precisos, y atendiendo la distinción que realiza el danés entre Fichte y el romanticismo, debería decirse que no se impugna la filosofía de Fichte en tanto que "idealismo subjetivo", sino, más bien, en tanto que posición teórica que contendría el germen de un "idealismo subjetivo". 
El punto capital de la interpretación que Kierkegaard hace de Fichte en su tesis doctoral no esconde misterio alguno: "el ego fichteano no coincide con el sí mismo existente". ${ }^{24} \mathrm{El}$ Yo trascendental de la Doctrina de la Ciencia es un principio formal y abstracto, "una infinitud en la que no hay ninguna finitud, una infinitud desprovista de todo contenido". ${ }^{25} \mathrm{La}$ subjetividad fichteana es negatividad infinita y recae en el docetismo: ${ }^{6}$ así como para los herejes cristianos el Logos no se hizo verdaderamente carne, el Yo fichteano se sustrae a todas sus determinaciones concretas.

Sin una referencia explícita a Fichte, pero como crítica a la concepción idealista de la subjetividad, los mismos reproches reaparecen en las obras de mayor densidad teórica de la primera autoría kierkegaardeana: El concepto de la angustia (Bebreget Angest, 1844) y el Postscriptum no cientifico y definitivo a Migajas Filosóficas (Afsluttende widenskabelig Efterskrift til de philosophiske Smuler, 1846). Vigilius Haufniensis, el autor pseudónimo de El concepto de la angustia, califica la pura auto-conciencia (rene Selvbevidsthed) como la máxima vaporosidad del Idealismo (Idealismens Luftighed). ${ }^{27} \mathrm{El}$ propósito último de la verdadera filosofía y el objetivo esencial de la vida son, de acuerdo con el pseudónimo, uno y el mismo: el auto-conocimiento. Sin embargo, este conocimiento de sí mismo no es, como según el pseudónimo pretende el Idealismo, un saber del Yo puro sino un actuar en referencia a la propia existencia individual, una relación práctica del individuo con su identidad singular. ${ }^{28}$ Precisamente esta singularidad vital, dirá el pseudónimo Johannes Climacus en el Postscriptum, es lo que está ausente en el Yo idéntico a sí

\footnotetext{
${ }^{24}$ Kangas, David, op. cit., p. 71.

25 SKS 1: 309 / CI: 296.

26 Véase SKS 1: 309 / CI: 296.

27 Véase SKS 4: 382 / CA: 192. El idealismo alemán, había dicho Kierkegaard en Sobre el concepto de ironía, radicalizaba una orientación ya inscripta en la filosofía kantiana: "con el criticismo, el Yo fue sumiéndose en la contemplación del Yo, este Yo adelgazó más y más hasta terminar convirtiéndose en un espectro, inmortal como el esposo de Aurora" (SKS 1: 308 / CI: 296).

28 Véase SKS 4: 382 / CA: 192 y SKS 4: 443 / CA: 248 - 249. La subjetividad de la cual habla Fichte, de acuerdo con el pseudónimo Vigilius Haufniensis, es abstracta y carece de auténtica concreción (Véase SKS 4: 439 / CA: 245).
} 
mismo del Idealismo: "El Yo-Yo es un punto matemático que no existe en absoluto; en consecuencia, cualquiera podría situarse allí sin representar un estorbo para los demás... El fabuloso Yo-Yo no es la identidad de la finitud con la infinitud, puesto que ni la una ni la otra son reales; trátase aquí de una fantástica unión de nubes, de un estéril abrazo, y la relación del Yo individual con esta aparición etérea nunca se explica". ${ }^{29}$

El punto final de nuestro recorrido es el libro La enfermedad mortal (Sygdommen til Doden) publicado en 1849 con la firma del pseudónimo AntiClimacus. Sobre el final de la Primera Parte de este escrito, bajo la figura de la desesperación desafío o del desesperado que "quiere ser sí mismo", Kierkegaard vuelve a analizar los límites y dificultades de la ironía y la subjetividad románticas. Este yo, consciente de su poder, pretende

disponer de sí mismo, o ser su propio creador, haciendo de su propio yo el yo que él quiere ser, determinando a su antojo todo lo que su yo concreto ha de tener consigo o ha de eliminar... Nuestro hombre no quiere revestirse con su propio yo, ni tampoco estima que su tarea haya de estar relacionada con el yo que se le ha dado, sino que personalmente quiere construirlo de raíz, encarnando aquella forma infinita. ${ }^{30}$

Resulta evidente que aquí se retoma la crítica al pensamiento romántico desarrollada en el escrito académico de 1841. Así como la exposición no identifica explícitamente esta figura de la conciencia desesperada con el romanticismo tampoco alude a la filosofía fichteana como su fuente teórica; empero, el autor de La enfermedad mortal sí incorpora explícitamente a Fichte en la exposición de las diversas modalidades de la desesperación. ${ }^{31}$ La mención aparece en el capítulo 1 del Libro III de la

\footnotetext{
${ }^{29}$ SKS 7: 180 / PC: 199.

${ }^{30}$ SKS 11: 182 / EM: 107.

${ }^{31}$ Esta referencia a Fichte merecería un tratamiento detallado que, por cuestiones de espacio, no es posible ofrecer. El lector interesado puede remitirse a Kangas (Kangas, David, "J. G. Fichte: From Transcendental Ego to Existence", pp. 74-78) y Janke (Janke, Wolfgang, "Das Phantastische und die Phantasie bei Hegel und Fichte im Lichte von Kierkegaards pseudonyme Schriften", en Entgegenseutungen.
} 
Primera Parte, sección en la cual se somete a análisis el comportamiento del yo cuando a éste se lo concibe como síntesis de finitud e infinitud. La fantasía es el órgano de lo infinito, la condición de posibilidad de toda reflexión y libertad puesto que sin ella el ser humano no podría trascender la realidad. Para Anti-Climacus la fantasía no es una facultad entre otras y en apoyo a su convicción recurre a Fichte:

En definitiva, los sentimientos, los conocimientos y la voluntad que haya en un hombre dependen de la fantasía que tenga, es decir, de cómo todas aquellas cosas se proyecten reflexivamente en la fantasía. La imaginación equivale a la reflexión infinitizadora, por lo que el viejo Fichte tenía mucha razón al suponer que la fantasía, incluso respecto del conocimiento, es el origen de las categorías. ${ }^{32}$

Pasemos en limpio algunas conclusiones tentativas. Kierkegaard entró en contacto con la filosofía de Fichte en un momento temprano de su formación intelectual. Este primer acercamiento, de carácter directo, provocó un influjo más bien subterráneo en su pensamiento. A continuación, como puede apreciarse en Sobre el concepto de la ironía, la relación del danés con Fichte estuvo mediada por la interpretación de Hegel y del hegelianismo danés (Hans Martensen): el idealismo de Fichte es, a raíz de su abstracción y subjetivismo, el origen histórico de la posición romántica. De 1844 a 1846 puede detectarse una reconfiguración teórica en torno a la imagen de la filosofía de Fichte. La Wissenchaftslehre se convierte, ahora, en un antecedente del pensamiento hegeliano; el idealismo fichteano acentúa cierto giro subjetivo presente en la filosofía crítica (Kant) que terminará de radicalizarse con el pensamiento especulativo (Hegel). ${ }^{33}$ En estas dos primeras etapas podemos confirmar un principio constante del pensamiento de Kierkegaard: el danés, por lo general, ni comprende ni critica los sistemas filosóficos en el plano de su elaboración y coherencia interna y conceptual sino en el registro de sus consecuencias y efectos

Studien zu Fichte-Konfrontation von Rousseau bis Kierkegaard, Amsterdam, Rodopi, 1994, pp. 159-186).

32 SKS 11: 147 / EM: 60.

${ }^{33}$ Véase SKS 7: 299 / PC: 324. 
culturales y existenciales. Por último, hacia el año 1847, se produce una reapropiación de motivos fichteanos que viene a coincidir con el renovado énfasis que el danés pone en ciertas problemáticas filosóficas. A la exposición y el análisis de esta singular apropiación de Fichte reservamos el punto iii.

\section{ii. Mirada panorámica de la reciente literatura Fichte- Kierkegaard}

Es conocida la posición que la historia de la filosofía le ha reservado a Kierkegaard: junto a Feuerbach, Marx y Schopenhauer (y, más tarde, Nietzsche) es uno de los más enconados enemigos de la filosofía hegeliana en particular y del idealismo alemán en general. Su solitaria voz se alzó desde los márgenes de Europa para denunciar la desmesurada racionalidad de la filosofía especulativa sirviendo de inspiración para dos de los más importantes movimientos de reacción contra la metafísica idealista y sus epígonos culturales: la teología dialéctica y la filosofía existencialista. El que sus diversos escritos lograran convertirse en uno de los respaldos teóricos del rechazo a los sistemas de pensamiento post-kantianos no se explica tanto por el hecho de que en ellos resonase el llamado a un nuevo realismo capaz de devolverle al mundo su independencia ontológica frente a la conciencia, ${ }^{34}$ sino, más bien, al hecho de que los textos kierkegaardeanos problematizaban la noción moderna de subjetividad permitiendo un severo cuestionamiento de la tesis idealista de la autonomía. ${ }^{35}$ Tanto la teología

${ }^{34}$ De hecho, un análisis pormenorizado de los escritos filosóficos de Kierkegaard (Migajas Filosóficas y Postscriptum) permite concluir que la gnoseología del danés supone, de alguna manera, un retorno a modelos pre-kantianos de idealismo (Berkeley). Sobre esta cuestión puede consultarse: Rodríguez, Pablo, "Elaboración del concepto de 'idealismo' en el Post-scriptum: Kierkegaard ante la superación hegeliana de Kant" en Solé, J. y Lerussi, N. (ed.), En busca del Idealismo. Las transformaciones de un concepto, Buenos Aires, RAGIF Ediciones, 2016, pp. 245- 267.

35 Odo Marquard indica que la crítica a la tesis idealista de la autonomía comienza ya con el mismo idealismo. Un análisis a fondo y minucioso del desarrollo de las filosofías de Fichte, Schelling y Kierkegaard “encuentra ora en el 'idealismo tardío' 
dialéctica como la corriente existencialista tenían en claro que el fundamento último de dicha crítica era de carácter religioso. Los teólogos, obviamente, no tenían mayores inconvenientes con la impronta religiosa de la obra del danés; sin embargo, consideraban que las intuiciones filosóficas de Kierkegaard se echaban a perder porque su pensamiento, tanto en su vocabulario como en su esquema expositivo, permanecía bajo el influjo de la filosofía idealista alemana. Por su parte, los filósofos existencialistas desconfiaban del rendimiento teórico del rechazo kierkegaardeano a la filosofía idealista debido al lastre teológico presente en los argumentos del danés.

Algunas de las más recientes lecturas de conjunto del danés se proponen restablecer el valor filosófico del ataque kierkegaardeano a la tesis idealista de la autonomía, prescindiendo, en la mayor medida posible, de las premisas teológicas sobre las cuales éste se asienta. Para lograr esta rehabilitación, se interpreta a Kierkegaard como un filósofo post-moderno o un teórico deconstructivista, dicho de otro modo, se lo presenta en los términos de un precoz pensador de la muerte del sujeto, en general, y de la muerte del sujeto idealista, en particular. Esta nueva recepción del corpus kierkegaardeano es el horizonte de comprensión sobre el cual se han venido desarrollando los más recientes intentos de actualización del diálogo FichteKierkegaard. Como punto de partida de nuestro análisis recurrimos a un párrafo de Roe Fremstedal que condensa paradigmáticamente el tenor de estos ensayos:

Los especialistas han indicado semejanzas estructurales entre Fichte y Kierkegaard en lo que respecta al modo en que ambos

ora en el idealismo global junto aquello que la crítica del idealismo por lo general echa de menos allí: el sentido de los límites de la autonomía humana, el sentido de la finitud, de la facticidad y del tú, el sentido para lo Otro de la razón y por ello también a fin de cuentas el sentido del poder absoluto de Dios" (Marquard, Odo, "Idealismo y Teodicea" en Las dificultades con la filosofía de la historia, trad. Ocaña, Valencia, Pre-Textos, 2007, p. 61). 
consideran la personalidad. ${ }^{36}$ Para Kierkegaard, los principales rasgos estructurales del yo son los siguientes: (1) el yo es una síntesis de finitud e infinitud, de necesidad y libertad, dicho yo, a su vez, (2) es auto-relacional y (3) al relacionarse consigo mismo, se relaciona con el poder que lo ha puesto. Las dos primeras características estructurales las comparte el danés con Fichte (y Schelling), mientras que la tercera es una negación del principio fichteano de auto-posición. Fichte acentúa el acto de autocreación, sugiriendo, de ese modo, que el sujeto se funda a sí mismo; por su parte, Kierkegaard retrata al yo como puesto por Otro. De todos modos, esto último no equivale a una fundamentación en un sentido fichteano o idealista; más bien, significa que el yo kierkegaardeano está desfondado (carece de fundamento), o que se fundamenta a sí mismo sobre el abismo. Esto se relaciona con el hecho de que, a diferencia de Fichte, Kierkegaard muestra una marcada preocupación por la pasividad y la negatividad, concentrándose en la desesperación, la angustia y el sufrimiento. ${ }^{37}$

El pasaje reproducido ilustra con claridad algunos de los puntos señalados. En primer lugar, confirma la innegable deuda terminológica y conceptual que tiene Kierkegaard con el idealismo alemán: el yo kierkegaardeano no es una sustancia sino un sujeto cuya esencia es la autoreferencialidad. ${ }^{38}$ En segundo lugar, permite visualizar el "giro anti-

${ }^{36} \mathrm{La}$ fuente primaria de esta reconstrucción de la posición kierkegaardeana es la descripción del sí mismo que abre La enfermedad mortal, extendida sin matices al resto de la producción del danés: "El hombre es espíritu. Mas, ¿qué es el espíritu? El espíritu es el yo. Pero ¿qué es el yo? El yo es una relación que se relaciona consigo misma, o dicho de otra manera: es lo que en la relación hace que ésta se relacione consigo misma. El yo no es la relación, sino el hecho de que la relación se relacione consigo misma [...] Una relación así derivada y puesta es el yo del hombre; una relación que se relaciona consigo misma y que en tanto se relaciona consigo misma, está relacionándose a un otro" (SKS 11: 129 - 130/ EM: 35 - 36).

${ }^{37}$ Fremstedal, Roe, "Kierkegaard's use of German Philosophy: Leibniz to Fichte" en Stewart, Jon (ed.), A Companion to Kierkegaard, Oxford, Blackwell, 2015, p. 44. 38 Véase Kosch, Michelle, Freedom and Reason in Kant, Schelling and Kierkegaard, New York, Oxford University Press, 2006, p. 200; véase Loncar, Samuel, "From Jena to 
teológico" que transforma al danés en un teórico de la muerte del sujeto: el Otro -ahora interno a la subjetividad- se convierte en la diferencia o negatividad que habita en el seno mismo del yo y hace que el sí-mismo difiera de sí mismo. ${ }^{39}$ Por último, el pasaje citado delimita, por lo menos en primera instancia, qué papel juega la filosofía fichteana frente a esta nueva comprensión de Kierkegaard: la producción filosófico-literaria del danés rivalizaría con la tesis fundamental de la Doctrina de la Ciencia, a saber, la idea de un yo que se pone a sí mismo. ${ }^{40}$ Lo que me importa destacar es que esta metamorfosis del Otro (alteridad) en diferencia (altaridad) ${ }^{41}$ condiciona el

Copenhagen: Kierkegaard's relations to German idealism and the critique of autonomy in The Sickness Unto Death" en Religious Studies, n 47, (2011), pp. 208 209 y Kangas, David, "J. G. Fichte: From Transcendental Ego to Existence”, p. 67. ${ }^{39}$ Véase Kangas, David, "J. G. Fichte: From Transcendental Ego to Existence”, p. 86 y Rasmussen, Anders, "Kierkegaard's notion of negativity as an epistemological and anthropological problem", en Cappelørn, N., Stewart, J. \& Deuser, H. (ed.), Kierkegaard Studies. Yearbook, 2004, New York/Berlin, Walter de Gruyter, 2004, p. 260.

40 Véase O'Neil Burns, Michael, Kierkegaard and the matter of Pbilosophy. A fractured dialectic, pp. 43-87 y Vermal, José Luis, "La crítica de la concepción idealista del sujeto en La enfermedad mortal de S. Kierkegaard", pp. 204-207. Para Kangas toda la autoría pseudónima de Kierkegaard hasta El concepto de la angustia tiene como objetivo volver manifiesto que en la subjetividad hay algo "anterior" y "más originario" que el movimiento fichteano de autoposición (véase Kangas, David, Kierkegaard's Instant. On Beginnings, Bloomington, Indiana University Press, 2007, pp. 85-197).

${ }^{41}$ El puntapié inicial para esta nueva comprensión de Kierkegaard se encuentra, por una parte, en la noción de "altaridad" de Mark Taylor: "En las profundidades de la interioridad yace, escondido, un Otro que nunca puede ser conocido. Aunque nada se acerca más a la conciencia que él, ese Otro no es personal, sino que permanece en un anonimato innombrable que sigue de cerca a la subjetividad. Esta exterioridad interior complica aún más la estructura de la autorrelación inherente a la autoconciencia. Kierkegaard, que fue influido por Schelling, expone la altaridad reconocida implícitamente, pero nunca de manera explícita, en la concepción de la subjetividad que tenía Hegel [...] con la retirada del Otro 'en' el yo, el Deus absconditus de Lutero y Calvino se convierte en el subjectus absconditus, que está implícito en el modernismo y que se hace explícito en el posmodernismo" (Taylor, 
modo en que los especialistas entienden la relación Fichte-Kierkegaard, puesto que dicha transformación le otorga preponderancia a un aspecto particular de la recepción crítica que el danés realiza del pensamiento de Fichte a través de la mediación hegeliana. Veamos esta cuestión en detalle.

De acuerdo con esta línea de interpretación, Kierkegaard afirma que la tendencia básica del yo es el movimiento por el cual éste se relaciona consigo mismo. El análisis de la existencia desplegado a lo largo de sus escritos revela, sin embargo, que esta tendencia queda trunca y que el yo nunca logra alcanzarse a sí mismo por completo. El gran problema del danés consiste en determinar cuál es la razón de este fracaso. Su respuesta puede resumirse del siguiente modo: no hay que imputar el malogramiento de este movimiento a cierta incapacidad del yo; más bien, debe ser atribuido a una suerte de incongruencia esencial de la subjetividad. Si los textos kierkegaardeanos elevan al rango de conceptos filosóficos experiencias tales como la angustia, la melancolía, el aburrimiento y la desesperación es porque hacia el interior de su economía argumentativa estas disposiciones anímicas son manifestaciones negativas de la libertad y, por este motivo, su

Mark, Después de Dios. La religión y las redes de la ciencia, el arte, las finanzas y la politica, trad. Tosas, Madrid, Siruela, 2011, pp. 146-148). Por otra parte, en el análisis que realiza Derrida de Temor y Temblor en su libro Dar la muerte: "Dios es el nombre de la posibilidad para mí de guardar un secreto que es visible en el interior pero no en el exterior. En cuanto hay esta estructura de la conciencia, de estar-consigo-mismo, de hablar, de decir, de producir algún sentido invisible; en cuanto tengo dentre de mí, gracias a la palabra invisible como tal, un testigo que los otros no ven y que, por tanto, es a la vez distinto de mí y más íntimo a mí que yo mismo... Dios está en mí, él es 'yo' absoluto, es esta estructura de la interioridad invisible que se llama, en el sentido kierkegaardeano, la subjetividad" (Derrida, Jacques, Dar la muerte, trad. Peretti y Vidarte, Barcelona, Paidós, 2000, pp. 103-104). Este 'otro', desde una perspectiva más afín a la comprensión existencialista-heideggeriana, ha sido leído como la afirmación del carácter insuperablemente finito del yo. Günter Figal, por ejemplo, ha señalado lo siguiente: "que la relación es puesta [por otro], significa, que ella no es a partir de sí misma lo que es. Dado que el yo no es fundamento de sí mismo, es un Faktum" (Figal, Günter, "Die Freiheit der Verzweiflung und die Freiheit im Glauben. Zu Kierkegaard Konzeption des Selbstseins und Selbstwerdens in der 'Krankheit zum Tode”, Kierkegaardiana XIII, (1984), p. 13). 
causa última tiene que ser remitida a la estructura esencial del yo. En este sentido, el estudio de estos temples afectivos viene a coincidir con una investigación regresiva de sus causas, esto es, con una elucidación de la fractura interna y originaria de la subjetividad. Aquello que en Hegel era tan sólo una figura determinada y pasajera en el desarrollo fenomenológico del espíritu, en Kierkegaard deviene la verdad más íntima del sujeto: el yo es desde el vamos un yo desgraciado porque estructuralmente tiene "su ser propio [Egentlige Vasen] de algún modo fuera de sí [udenfor sig]... está siempre ausente de sí mismo, nunca está presente en sí mismo". ${ }^{42}$ La conciencia, por tanto, no se pone a sí misma sino que se encuentra (o, mejor dicho, se recibe) a sí misma, ella, como escribe Kierkegaard en su obra inconclusa Johannes Climacus eller De omnibus dubitandum est, "se presupone [forudsatter] a sí misma [sig selv]". ${ }^{43}$ Esta diacronía interna del yo es la "condición de imposibilidad" de cualquier proyecto de auto-fundación y, por ende, la impugnación radical de la tesis idealista de la autonomía. ¿De qué modo se refleja Fichte en el espejo de esta nueva interpretación del danés? Como su imagen invertida. El signo característico de la subjetividad fichteana ya no es aquella falta de concreción de la cual Kierkegaard se quejaba en su tesis de 1841 sino su identidad inquebrantable. Con todo, esta perspectiva no es completamente ajena al discurso del danés, puesto que el apoyo para esta comprensión del pensador alemán se encuentra, también, en Sobre el concepto de Ironía donde Kierkegaard caracteriza el sistema fichteano como la filosofía de "la infinita identidad del Yo consigo mismo". ${ }^{44}$ La subjetividad de la cual habla Fichte, es plenamente coincidente consigo mismo, carece de cualquier clase de fisura. El Yo fichteano es esencialmente auto-transparente por ser siempre presente a sí mismo. Así lo entiende David Kangas a partir del siguiente fragmento de la Segunda Introducción a la Doctrina de la Ciencia:

... el Yo retorna sobre sí mismo. ¿No existe por tanto para sí antes de ese retornar e independientemente del mismo? ¿no ha de existir ya para sí para poder convertirse en el objetivo de su actuar? [...] Respondo: de

42 SKS 2: 216 / OO I: 234. Véase Kangas, David, Kierkegaard's Instant, pp. 84 - 85.

${ }^{43}$ SKS 18: 159 / JC: 129.

${ }^{44}$ SKS 1: 209 / CI: 297. 
ninguna manera. Sólo por ese acto y únicamente por él, por medio de un actuar sobre un actuar, por un actuar determinado que no viene precedido por ningún actuar, llega el Yo a ser originariamente para sí mismo. ${ }^{45}$

Es cierto que Fichte afirma que al Yo se enfrenta un no-Yo, pero en la medida en que éste es producto de aquel, el no-Yo ni constituye una verdadera oposición para el Yo (no es un auténtico otro) ${ }^{46}$ ni es el punto de partida efectivo para un auténtico desgarramiento del Yo. ${ }^{47}$ El Yo fichteano, en suma, se pone a sí mismo y esta capacidad de auto-fundamentación es la garantía de su autonomía en un nivel teórico y, más fundamentalmente, en un nivel práctico. De acuerdo con Kangas y O’Neill Burns, el leit motiv de El concepto de la angustia es la problematización de este tópico idealista. Para Fichte, argumentan ambos autores, el pensamiento no puede remontarse por detrás de la libre auto-posición del Yo por lo cual la pregunta que interroga por la pre-historia del Yo debe ser rechazada sin vacilaciones. ${ }^{48}$ Para el pseudónimo Vigilius Haufniensis, por el contrario, justamente se trata de retroceder un paso más atrás y preguntar por el fundamento mismo de esta libertad. ${ }^{49}$ Será el análisis psicológico de la experiencia de la angustia lo que eche luz sobre esta cuestión. No obstante, aquello que la investigación en torno al fenómeno de la angustia nos revela es que, precisamente, ese fundamento buscado es un no-fundamento, la nada que

\footnotetext{
45 GA I, 4: 213 / IntroDC: 75.

46 Para Kangas no habría una auténtica alteridad porque esta, en último término, derivaría de la identidad del yo consigo mismo (véase Kangas, David, "J. G. Fichte: From Transcendental Ego to Existence”, p. 86).

47 "La dialéctica existente entre el Yo y el no-Yo es siempre unilateral, puesto que el no-Yo carece, básicamente, de autonomía. El no-Yo es una mera manifestación (nur eine Erscheinung) del Yo. La síntesis, que se produce entre el no-Yo y el Yo, es ya siempre el trabajo solitario del Yo... En este sentido puede decirse: el principio de Identidad tiene una primacía incondicional sobre el principio de Contradicción" (Schmidinger, Heinrich, "Kierkegaard und Fichte", p. 530).

48 Véase GA I, 2: 260 / FDC: 17.

49 Véase Kangas, David, Kierkegaard's Instant, pp. 162-163 y O’Neill Burns, Michael, Kierkegaard and the matter of Philosophy. A fractured dialectic, p. 43.
} 
engendra la angustia, ${ }^{50}$ un fondo oscuro, un abismo (Afgrund), del cual surge toda libertad y actividad. ${ }^{51}$ A través de la angustia, escribe O’Neill Burns, "el sí mismo se torna consciente de la libertad abisal que vive en el corazón de su propia existencia". ${ }^{2}$ Trazando un puente entre El concepto de la angustia y La enfermedad mortal, Kangas concluirá lo siguiente:

incluso cuando Kierkegaard nos habla del yo "que se fundamenta en el poder que lo ha puesto" el modo en que éste se funda no opera de acuerdo con la lógica del fundamento que encontramos en los textos de Fichte (o en los textos de otros idealistas). El yo se fundamenta, finalmente, sobre un abismo. Pero reconocer la radical falta de fundamentación del yo significa, básicamente, revertir la trayectoria fichteana de concebir al yo como fundamento..$^{53}$

Dentro del conjunto de especialistas que adhieren a este "nuevo" Kierkegaard no falta quienes aceptan que esta visión del pensamiento fichteano es injusta y merece ser revisada. Este es, esencialmente, el caso de O’Neill Burns. Ante todo, es preciso admitir que el Fichte berlinés ya había desarrollado algunas de las objeciones que el danés esgrimirá, décadas después, en contra de la noción idealista de subjetividad. ${ }^{54}$ Más interesante, sin embargo, es el reconocimiento de que incluso en la filosofía fichteana del período de Jena, o por lo menos en una lectura no egológica de esta filosofía, ${ }^{55}$ es posible encontrar la anticipación de temáticas

\footnotetext{
${ }^{50}$ Véase SKS 4: 347 / CA: 159.

51 Véase SKS 4: 365 - 366 / CA: 176 - 177.

${ }^{52}$ O'Neill Burns, Michael, Kierkegaard and the matter of Philosophy. A fractured dialectic, p. 44.

${ }^{53}$ Kangas, David, "J. G. Fichte: From Transcendental Ego to Existence”, p. 87.

${ }^{54}$ Véase O'Neill Burns, Michael, Kierkegaard and the matter of Philosophy. A fractured dialectic, p. 12.

55 Para O’Neill Burns el máximo exponente de esta interpretación es Dieter Henrich. A pesar de defender una lectura que pondera ciertos elementos "existencialistas" en Fichte, Henrich considera que la oposición dialéctica entre el Yo y el no-Yo es completamente interna a la conciencia y no refiere a nada más allá de la subjetividad (véase O'Neill Burns, Michael, Kierkegaard and the matter of Philosophy. A fractured dialectic, pp. 12 - 13).
} 
kierkegaardeanas. En este sentido, la atención se vuelve en dirección a la categoría de "Ansto $\beta$ ", específicamente al tratamiento que recibe este concepto a manos de Daniel Breazeale y Slavoj Žižek. No resulta difícil entender por qué esta temática del primer Fichte resulta tan atractiva para los lectores postmodernos de Kierkegaard. ${ }^{56}$ En primer lugar, porque el Ansto $\beta$ es un suceso que no es puesto por el Yo pero que al obstaculizar al $Y o$ se convierte en el impulso originario para su actividad teórica y práctica. ${ }^{57}$ Si no hay Ansto $\beta$, el Yo no podría constituirse a sí mismo:

El $A n s t o \beta$ (no puesto por el Yo ponente) acaece sobre el Yo, en la medida en que el Yo es agente; y, por consiguiente, es un Ansto $\beta$ sólo en la medida en que él es agente: su posibilidad es condicionada por la actividad del Yo: si no hay actividad del Yo, no hay Ansto $\beta$. A su vez, la actividad de determinación del Yo por sí mismo estaría condicionada por el $A n s t o \beta$ : si no hay $A n s t o \beta$, no hay autodeterminación. ${ }^{58}$

En segundo lugar, porque a pesar de no ser algo puesto por el Yo, el Ansto $\beta$ es un acontecimiento interno al Yo. Dicho de otro modo: el Ansto $\beta$

56 El concepto de Ansto $\beta$ no juega ningún papel esencial en el artículo de Schmidinger sobre la relación Fichte-Kierkegaard. Para este autor es el Yo quien se da a sí mismo el $A n s t o \beta$ contra-poniéndose un no-Yo (véase Schmidinger, Heinrich, "Kierkegaard und Fichte", p. 530).

${ }^{57}$ Véase Breazeale, Daniel, "Check or Checkmate? On the Finitude of the Fichtean Self', en Ameriks, K. y Sturma, D. (ed.), The Modern Subject: Conceptions of the Self in Classical German Philosophy, Albany, State University of New York Press, 1995, p. 102.

${ }^{58}$ GA I, 2: 356/ FDC: 90. 
no es el "no-Yo frente al Yo" sino un "no-Yo en el Yo" 59 o, incluso, "anterior al Yo". ${ }^{60}$

Es extraño que O’Neill Burns no pase revista al empleo que algunos especialistas en la obra del danés realizan de la categoría fichteana de Ansto $\beta$ para aclarar algunos conceptos o pasajes de la filosofía kierkegaardeana. John Davenport echa mano del concepto de $A$ sto $\beta$ en un artículo en el cual explora la noción de "bildet Fribed" (libertad enredada) de El concepto de la angustia. Davenport considera que, en el marco de la argumentación del pseudónimo Vigilius Haufniensis, las palabras divinas que prohíben comer el fruto del árbol del Bien y del Mal cumplen la misma función que el Ansto $\beta$ fichteano: ellas despiertan al yo al enfrentarlo con un límite y, de ese modo, lo hacen consciente de su propia libertad. ${ }^{61}$ En su análisis de Johannes

59 "En claro contraste con la Ding noumenal kantiana, que afecta a nuestros sentidos, la $A n s t o \beta$ no proviene del exterior, y en sentido estricto es ex-timo un cuerpo extraño no asimilable que aparece en el núcleo mismo del sujeto; como lo subraya el propio Fichte, la paradoja del $A n s t o \beta$ reside en que es 'puramente subjetivo' y, al mismo tiempo, no producido por la actividad del Yo" (Žižek, Slavoj, El espinoso sujeto. El centro ausente de la ontología política, trad. Piatigorsky, Buenos Aires, Paidós, 2001, pp. 56-57).

${ }^{60}$ Véase O'Neill Burns, Michael, Kierkegaard and the matter of Philosophy. A fractured dialectic, p. 11. Vale la pena contrastar estas reelaboraciones del concepto de Ansto $\beta$ con la que ofrece Günter Zöller: “... es el Yo mismo que se da originariamente la limitación y la concibe, por así decirlo, con posterioridad como efectuada por los objetos exteriores. Fichte fija la forma residual de la determinación externa como un 'tope' (Anstoß), a la que el Yo está sujeto y al que motiva por primera vez hacia una (contra)posición de un mundo de objetos... La resistencia misma no es entendida por Fichte en sentido objetivista como impulso exterior, sino como experiencia del límite del Yo, que se topa con los confines de su efectividad en el determinada y para lo cual objetiviza el propio toparse con algo (Anstoßen-an-etwas) en un ser topado por algo (Anstoßenwerden-von-etwas)" (Zöller, Günter, Leer a Fichte, p. 50). Esta caracterización es la que entra en juego en la lectura de Schimidinger (mencionada en nota 56).

${ }^{61}$ Véase Davenport, John, “"Entangled Freedom’ Ethical Authority, Original Sin, and Choice in Kierkegaard's Concept of Anxiety", Kierkegaardiana, No 21, (2001)", p. $141 \mathrm{ss}$. 
Climacus, David Kangas presta especial atención a la categoría kierkegaardeana de Sammenstodet (colisión). "La conciencia -escribe Kierkegaard- aparece precisamente por la colisión, en la misma medida en que presupone la colisión". ${ }^{2}$ De acuerdo con Kangas, lo que "condiciona la emergencia de la conciencia es, ciertamente, una interrupción de la inmediatez: la conciencia se encuentra a sí misma, se pone a sí misma, únicamente encontrándose interrumpida". ${ }^{63}$ Ahora bien, en esta explicación del surgimiento de la conciencia el intérprete norteamericano encuentra una reminiscencia de la filosofía fichteana, puesto que "Fichte postula un $A$ sto $\beta$ que interrumpe la pura actividad tética del ego absoluto. La pura autoposicionalidad del ego colisiona con algo 'otro"'. 64

¿Qué se sigue de esta reconsideración del pensamiento fichteano? Una profunda modificación de los términos en los cuales se piensa la relación Fichte-Kierkegaard. Lejos de transitar dos caminos de pensamiento enfrentados a partir de sus opciones teóricas inaugurales, tanto la filosofía de Kierkegaard como la del primer Fichte pondrían en evidencia el carácter finito de la subjetividad. El pensador danés, por tanto, se habría dedicado a profundizar de forma consciente y deliberada un rumbo teórico abierto por el pensador alemán.

\section{iii. Propuesta de nueva perspectiva}

El principal déficit de las recientes interpretaciones de Kierkegaard es que, al prescindir de sus presupuestos religiosos, mutilan su proyecto filosófico. Es necesario, por tanto, retornar desde la diferencia (altaridad) al Otro (alteridad). Más que una recaída de la filosofía en la teología, este regreso debe considerarse como un intento por obtener un rendimiento filosófico a partir de ciertos contenidos teológicos presentes en la obra kierkegaardeana. Dicho movimiento de retorno permitiría reconfigurar dos aspectos valiosos presentes tanto en las lecturas postmodernas del danés

\footnotetext{
${ }^{62}$ SKS 15: 58 / JC: 104.

${ }^{63}$ Kangas, David, Kierkegaard's Instant, p. 85.

${ }^{64}$ Ibid., p. 210.
} 
como en las investigaciones sobre la relación Fichte-Kierkegaard desarrolladas a la luz de dichas lecturas. Las interpretaciones postmodernas están en lo cierto cuando afirman que los escritos del danés ponen en cuestión la tesis idealista de la autonomía; sin embargo, a diferencia de lo que ellas plantean, nuestra posición es que la filosofía de Kierkegaard no conduce al abandono de la noción de autonomía, sino a su des-potenciación o des-centramiento ${ }^{65}$ y ello a través de una nueva concepción del yo desarrollada, fundamentalmente, en los principales escritos de la segunda autoria: Las obras del amor (Kjarlighedens Gjerniger, 1847), La enfermedad mortal y Ejercitación del cristianismo (Indovelse $i$ Christendeom, 1850). A partir de esta nueva comprensión global del pensamiento del danés se abre la posibilidad de un nuevo acercamiento entre Kierkegaard y Fichte, que puede ser pensado no sólo "de Berlín a Copenhague", como tradicionalmente hacían los especialistas, ${ }^{66}$ sino también, y principalmente, "de Jena a Copenhague", como sugieren algunas de las lecturas postmodernas. Siguiendo una breve consideración realizada por Habermas en Pensamiento Postmetafísico, nuestra propuesta hermenéutica, se define por un desplazamiento del punto de comparación entre ambos pensadores desde la categoría de Ansto $\beta$ hacia el concepto de Aufforderung. ${ }^{67}$ En pocas palabras: la reconfiguración (des-

${ }^{65}$ Para un análisis de la categoría de "des-centramiento" consultar Honneth, Axel, "Autonomía descentrada. Consecuencias de la crítica moderna del sujeto para la filosofía moral" en Crítica del agravio moral. Patologías de la sociedad contemporánea, trad. Diller, Buenos Aires, Fondo de Cultura Económica, 2009, pp. 275-292.

${ }^{66}$ Vale la pena mencionar que, en su artículo del año 1982, Heinrich Schmidinger hacía la siguiente consideración en torno al significado que tuvo la lectura de El destino del hombre en el joven Kierkegaard: “¿Qué toma Kierkegaard de Fichte? Desde la perspectiva de la mera presentación del estado de la cuestión nada más que dos determinaciones formales: en primer lugar, que el hombre esta libremente enfrentado a la Naturaleza y la supera, y, en segundo lugar, que él experimenta la determinación de su libertad a través de un poder otro y superior" (Schmidinger, Heinrich, "Kierkegaard und Fichte", p. 515). Lamentablemente el especialista alemán se limita a constatar esta influencia fichteana sin profundizar sus consideraciones.

67 "Fichte había deducido el yo individual de que un sujeto aislado no tiene más remedio que oponerse a otro en una relación intersubjetiva. La necesidad de un 
potenciación) del concepto de autonomía que Kierkegaard desarrolla entre 1847 y 1849 supone una comprensión intersubjetiva del yo de "inspiración" fichteana. ${ }^{68}$

encuentro entre ego y alter ego resultaría de un yo que, paradójicamente, se ha puesto él mismo, sólo puede tornarse consciente de sí en el modo de una subjetividad vuelta a la acción... Pues bien, esta peculiar figura de pensamiento que representa la posición de sí mismo, Kierkegaard se la apropia hasta el punto de interpretar la auto-referencialidad como un relacionarse consigo mismo, en que a la vez me relaciono con un otro previo, del que esa relación depende" (Habermas, Jürgen, Pensamiento postmetafísico, trad. Jiménez Redondo, Madrid, Taurus, 1990, p. 203). "Fichte había puesto en juego dos temas que Humboldt y Kierkegaard hacen suyos desde una perspectiva en la que el pensamiento histórico había introducido una mudanza: individualidad e intersubjetividad lingüística así como individualidad e identidad biográfica. El primer tema viene unido con el segundo por la idea de que es menester la apelación, la exigencia o la expectativa del prójimo para despertar en mí la conciencia de la actividad que tiene en mí su fuente" (Ibid., p. 204).

${ }^{68}$ Nuestra lectura, por tanto, se opone a aquellas que realizan, por un lado, Vermal y, por otro, Hühn y Schwab. Vermal considera que el principal antagonista de La enfermedad mortal es el concepto fichteano de subjetividad trascendental, cuya superación implicaría la apertura del yo a su fundamento religioso (véase Vermal, Juan Luis, "La crítica de la concepción idealista del sujeto en La enfermedad mortal de S. Kierkegaard", pp. 206-207). Hühn y Schwab, por su parte, consideran que el libro de Anti-Climacus profundiza la crítica de Schelling a aquel concepto de autonomía que se desprende de los primeros escritos de Fichte (véase Hühn, Lore y Schwab, Phillip, "Kierkegaard and German Idealism" en Lippit, John \& Pattison, George (ed.), The Oxford Handbook of Kierkegaard, Oxford, Oxford University Press, 2013, pp. 80-84). La lectura de Vermal, inscripta en la línea de lo que hemos denominado recepciones postmodernas del danés, tiende a borrar el carácter personal del Otro sobre el cual se fundamenta el yo (véase, p. 212) y, por este motivo, no reconoce la influencia positiva de Fichte en el nuevo modelo de sujeto propuesto por Kierkegaard. Por otra parte, si bien es cierto que en su primera autoría y, especialmente en El concepto de la angustia, Kierkegaard se sirve de Schelling para ir "más allá" de Fichte; en contra de lo propuesto por Hühn y Schwab, consideramos que en La enfermedad mortal la "crítica" al modelo egológico de sujeto se realiza con categorías que, si bien provienen de Schelling, deben ser rastreadas, en última instancia, hasta Fichte. 
El punto de partida es la "reacción" kierkegaardeana frente a las primeras secciones del célebre capítulo IV de la Fenomenología del Espiritu. ¿Qué es lo que impresiona al danés del texto hegeliano?69 La lectura de Kierkegaard retiene cuatro cuestiones principales: i) que al comienzo de la interacción los participantes se encuentran en un mismo nivel (se trata de dos individuos ya maduros), ii) que el proceso de interacción deriva en el establecimiento de una relación asimétrica entre los participantes (el resultado de la interacción arroja una autoconciencia vencedora y una vencida: "una es la conciencia independiente que tiene por esencia el ser para sí, otra la conciencia dependiente, cuya esencia es la vida o el ser para otro; la primera es el señor, la segunda el siervo") ${ }^{70}$, iii) que este resultado asimétrico contradice la pauta de reciprocidad presente en el concepto mismo de reconocimiento ("[los] extremos se contraponen, siendo el uno sólo lo reconocido y el otro solamente lo que reconoce" "71 y iv) que la causa de esta asimetría hay que buscarla en el hecho de que cada uno de los participantes ingresa a la relación con la pretensión de confirmar su independencia, esto es, aquello que busca cada autoconciencia no es el mutuo reconocimiento sino el ser reconocida por la otra. ${ }^{72}$ Kierkegaard acepta la tesis básica de la teoría hegeliana del reconocimiento: "cada extremo es para el otro el término medio a través del cual es mediado y unido consigo mismo", ${ }^{73}$ es decir, el yo logra constituir plenamente su

${ }^{69}$ Nos guiamos por el artículo de Arne Grøn, "Reconocimiento y comunicación. La ética entre Hegel y Kierkegaard", Estudios de Filosofía, trad. Muñoz Fonnegra, N ${ }^{\circ}$ 32, (2005), pp. 27-40.

${ }^{70}$ Hegel, George, Fenomenología del Espiritu, trad. Roces, Buenos Aires, Fondo de Cultura Económica, 1992, p. 117.

${ }^{71}$ Ibid., p. 115.

${ }^{72}$ Por este motivo, la búsqueda del reconocimiento decanta en una interacción de carácter agonístico: "el comportamiento de las dos autoconciencias se halla determinado de tal modo que se comprueban por sí mismas y la una a la otra mediante la lucha a vida o muerte. Y deben entablar esta lucha, pues deben elevar la certeza de sí misma de ser para sí a la verdad en la otra y en ella misma" (Ibid., p. 116).

${ }^{73}$ Ibid. 
identidad, su autonomía, a través del vínculo con otro. ${ }^{74}$ No obstante, considera que esta autorrealización es posible únicamente si la relación intersubjetiva que la promueve opera en conformidad a un modelo de interacción capaz de corregir los déficits detectados en la idea hegeliana de una "lucha por el reconocimiento". Justamente, el tema principal que abordan las principales obras del danés posteriores al Postscriptum es la exposición de un modelo de relación con el otro alternativo al descripto por Hegel que reelabora y prolonga, en un sentido ético-existencial, algunos de los elementos presentes en el concepto fichteano de Aufforderung. ${ }^{75}$

La tesis de una conformación intersubjetiva de la identidad personal se esboza en las páginas iniciales de La enfermedad mortal. Constituirse como un yo supone la actividad de relacionarse consigo mismo, en el sentido de una auto-determinación del propio ser; pero el poder de autodeterminación, la libertad, no es algo que el yo pueda poner en sí mismo. Afirmar esto último, sin embargo, no significa una anulación de la libertad del yo sino el reconocimiento de que el yo adquiere su libertad en una

\footnotetext{
74 Véase SKS 11: 193 / EM: 122-123. "Dado que la conciencia de sí mismo está determinada por el reconocimiento intersubjetivo del otro, se sigue que el status de ese otro es el factor determinante del nivel de la autoconciencia" (Stewart, Jon, Kierkegaard's Relation to Hegel Reconsidered, p. 585). "Tal fundamento es: el momento desde donde el yo se comprende a sí mismo, el medio a través del cual se siente obligado a su mayor posibilidad y ante el que el yo es 'este yo', ya que todo yo tiene siempre un ser-enfrente, con el que se comunica de una forma peculiar" (Jarauta Marion, Francisco, Kierkegaard. Los límites de la dialéctica del individuo, Cali, Cuadernos del Valle, 1975, p. 29).

${ }^{75}$ Sin descartar la posibilidad de una lectura directa de los textos de Fichte en los cuales aparece el concepto de Aufforderung, cabe señalar una serie de fuentes intermedias a partir de las cuales Kierkegaard tuvo algún tipo de contacto con este concepto fichteano. En primer lugar, hay que mencionar una cita de Hegel en sus Lecciones sobre Historia de la Filosofía. En segundo lugar, las lecciones de Hans Martensen sobre los Fundamentos del Derecho Natural y la Ética. Por último, la reelaboración que de la temática realiza Schelling en su Sistema del Idealismo Trascendental. Para un análisis de las mediaciones entre Kierkegaard y Fichte puede consultarse: Kosch, Michelle, "The Ethical context of Either / Or", Konturen, vol. VII, (2015), pp. 84 - 101.
} 
referencia constante a un otro. El yo, en suma, al relacionarse consigo mismo se relaciona con un otro ${ }^{76} \mathrm{y}$, a su vez, al relacionarse con otro se relaciona consigo mismo. ${ }^{77}$ La tarea de todo individuo, por tanto, es la de relacionarse consigo mismo de modo tal que le sea posible llegar a ser sí mismo. Esto es: la tarea de todo individuo es una correcta auto-determinación, es decir, un llegar a ser libre. ${ }^{78}$ Este proceso no podría ponerse en marcha, ni desarrollarse, si el individuo no se comprendiese a sí mismo como un ser capaz de ser libre. ¿Cómo alcanza el individuo la consciencia de sí mismo como un ser capaz de libertad?79 Esta pregunta concita la atención del danés en Ejercitación del

${ }^{76}$ Véase SKS 11: 130 / EM: 36.
${ }^{77}$ Dado que en la segunda parte de La enfermedad mortal Kierkegaard identifica la desesperación con el pecado y el pecado como una relación fallida con Dios, el origen último del malestar existencial no es el mero fracaso en la actividad autorelacional sino que la causa del déficit en la relación con uno mismo debe buscarse en el vínculo con Dios.

78 “... la libertad consiste en estar en sí mismo” (SKS 4: 224 / MF: 36). “... en el mundo del espíritu constituye el bien supremo el llegar a ser uno dueño de sí mismo -y ayudar amorosamente a otro para que espiritualmente sea sí mismo, libre, independiente, dueño; en una palabra, ayudarlo para que permanezca idéntico consigo mismo, representa el mayor beneficio que se puede hacer a un hombre" (SKS 9: 272 / LOA II: 113).

${ }^{79}$ Esta pregunta, en definitiva, es, por una parte, el tema de fondo que vertebra de principio a fin la teoría kierkegaardeana de la "comunicación de poder" (Kunnens Meddelse). Precisamente el "poder" que debe ser comunicado al individuo es el de su libertad; no obstante, la conciencia del sí mismo como un ser libre no puede ser recibida de forma directa Como señala Sergio Muñoz Fonnegra: "La comunicación de poder... al tener por objeto una realización... no puede ser dosificada, ni comunicada directamente, pues ello equivaldría a una objetivación del autoconocimiento... si dicho devenir-subjetivo ha de poderse comunicar, es necesaria una nueva forma de comunicación que coloque al individuo en relación con su existencia y lo impela a poner una y otra vez su sí mismo como la meta a la cual aspira" (Muñoz Fonnegra, Sergio, "La comunicación existencial: Kierkegaard y el problema del reconocimiento" en Acosta López, María (ed.), Reconocimiento y diferencia. Idealismo alemán y hermenéutica: un retorno a las fuentes del debate contemporáneo, Bogotá, Siglo de Hombres Editores/Universidad de los Andes, 2010, p. 177). Una 
Cristianismo. Para Kierkegaard, el yo se sabe libre, deviene sí mismo, a través de una acción libre, pero para que esta acción acontezca el individuo tiene que ser conducido hacia sí mismo, esto es, debe ser invitado por un otro a tomar la decisión de ejercer o no ejercer su libertad:

... lo que más propiamente ha de entenderse por atraer en verdad hacia sí, depende de la peculiaridad de lo que ha de ser atraído. Si esto es un yo, entonces atraerlo verdaderamente hacia sí no puede significar meramente que se le aparta de ser si mismo, de suerte que se le atraiga de tal manera que, haya perdido su entera consistencia propia, por el hecho de haber sido atraído a lo que lo atrajo hacia sí. No, respecto de lo que verdaderamente es un yo, atraer de esta manera sigue siendo un engaño... No, cuando lo que ha de ser atraído es en sí mismo un yo, atraerlo en verdad significa por lo pronto ayudarlo a que verdaderamente sea sí mismo, para así atraerlo hacia sí, o significa que en y con la atracción hacia sí se le ayuda a ser sí mismo. - Por lo tanto, atraer en verdad tiene aquí un doble significado: primero, hacer que el yo que ha de ser atraído sea sí mismo, y esto supuesto atraerlo hacia sí.

Y ahora, ¿qué significa ser un yo? Significa que se es una duplicidad. Por lo cual en este sentido 'atraer en verdad hacia sí' significa una duplicidad. El imán atrae al hierro hacia sí; pero el hierro no es ningún yo, por lo cual en este sentido atraer hacia sí es algo sencillo. Mas un yo es una duplicidad, es libertad; por lo cual en este sentido atraer hacia sí significa enfrentar a una elección. Cuando es atraído el hierro no hay ni puede hablarse de ninguna elección. Mas a un yo solamente le puede atraer otro en verdad mediante una elección; de suerte que atraer en verdad hacia sí es algo conjuntamente determinado. ${ }^{80}$

Con esta solución, el danés retoma el núcleo esencial de los $\S 3$ y $§ 4$ del Fundamento del derecho natural (Grundlage des Naturrechts, 1796/97) y del $\S$ 18 de la Ética (Das System der Sittenlehre nach den Prinzipien der Wissenschaftslehre, 1798). ¿Cómo es posible, se pregunta Fichte, que el yo adquiera conciencia de su actividad causal libre? La tesis de fondo del filósofo alemán es que

apreciación similar en Grøn, Arne, "Reconocimiento y comunicación. La ética entre Hegel y Kierkegaard", p. 39.

${ }^{80}$ SKS 12: 163 / EC: 223-224. 
mientras el yo permanezca cerrado sobre sí mismo es incapaz de acceder a la conciencia de su libertad puesto que para ello es necesario que capte en su experiencia, en el flujo de sus vivencias, una presencia involuntaria o, como dice Fichte, el yo tiene que percibir un "choque (Ansto $\beta$ ) externo".81 $\mathrm{El}$ aporte más original de la propuesta fichteana reside en el hecho de que este choque externo es concebido en los términos de una Aufforderung. Al tomar conciencia de este requerimiento el individuo "se encuentra como algo que podría operar aquí, que es exhortado a operar, pero que también podría abstenerse". ${ }^{82} \mathrm{El}$ individuo, por tanto, accede a la comprensión de su carácter libre al comprender que su actitud frente a esa influencia externa no es una reacción mecánica sino una respuesta voluntaria. Y ello porque no ha sido coaccionado a la acción, sino solicitado a ella. Ahora bien, en la medida en que el yo capta esta influencia externa como una invitación al ejercicio de su libertad, entiende, también, que la misma debe llegarle necesariamente desde un ser libre. ${ }^{83} \mathrm{El}$ yo, en suma, se constituye libre y racional si es el tú al cual otro yo se dirige: "Mi yoidad -escribe Fichte en su Sittenlehre-, y mi autonomía en general, está condicionada por la libertad del otro". 84

${ }^{81}$ Véase GA I, 3: 343 / FDN: 129.

${ }^{82}$ GA I, 3: 343 / FDN: 129. Expresado en los términos de la Sittenlehre: “... pienso mi autodeterminación como algo dado en aquel requerimiento, y me soy dado a mí mismo como libre en el concepto de ese requerimiento" (GA I, 5: 200 / E: 256). 83 Véase GA I, 3: 345 / FDN: 131. Como comenta Arrese Igor: "Si el efecto de la exhortación debió ser previsto por el fundamento de la acción de exhortación, en la medida en que este debió formarse el concepto de este efecto previamente a la acción, entonces esta acción es explicable sólo en términos de conocimiento, y no puede ser explicada en base a juegos de fuerzas naturales. Pero una acción que puede ser explicada sólo en términos de conocimiento debe tener como causa necesariamente a un ser racional, que actúe del mismo modo que el yo" (Arrese Igor, Héctor, "El rol de la intersubjetividad en la constitución de la autoconciencia. Acerca de la influencia fichteana en la Ethik de Hermann Cohen", Revista Latinoamericana de Filosofía, Vol. XXXIV, nº 2, (2008), pp. 318 - 319).

${ }^{84}$ GA I, 5: 201 / E: 257. La noción de una autonomía descentrada, por lo visto, ya está presente en Fichte; por lo cual, no es del todo correcto plantear, como por ejemplo lo hace Samuel Loncar (véase Loncar, Samuel, "From Jena to Copenhagen: 
Veamos en mayor profundidad algunos de los elementos que la Aufforderung de Fichte y la Indbydelse de Kierkegaard ponen en juego a la hora de pensar el rol de las relaciones intersubjetivas en la constitución del yo.

1. La escena inicial del devenir humano a partir de la relación intersubjetiva que describen Fichte y Kierkegaard difiere de la que narra Hegel. Ya no se trata de una interacción horizontal de carácter agonal sino de un vínculo vertical de carácter pedagógico. Para Fichte, "la exhortación a la espontaneidad libre es lo que se llama educación". ${ }^{85}$ Kierkegaard, por su parte, entiende esta invitación a la libertad en los términos de una "mayéutica cristiana". ${ }^{86}$ En este modelo de interacción el otro no aparece originariamente como un antagonista o un obstáculo, ${ }^{87}$ sino como un potencial auxiliar. ${ }^{88}$ La relación intersubjetiva, en su comienzo, posee un carácter necesariamente asimétrico y unilateral: un participante de la relación juega un rol pasivo y el otro uno activo. Del lado pasivo, encontramos un sujeto inmaduro, que todavía no se sabe libre; del lado activo, un sujeto ya

Kierkegaard's relations to German idealism and the critique of autonomy in The Sickness Unto Death", pp. 208-212), que la discusión del concepto de autonomía desarrollada en La enfermedad mortal debe contraponerse radicalmente a la filosofía fichteana.

${ }^{85}$ GA I, 3: 347 / FDN: 134.

86 Véase SKS 9: 274 ss / LOA II: 117 ss.

${ }^{87}$ Véase Gaudio, Mariano, "El estado natural del hombre es el Estado", Revista de Estud[i] os sobre Fichte, No 1, (2010), p. 3.

${ }^{88}$ Ya en el breve texto Von der Sprachfäbigkeit und dem Ursprung der Sprache (Sobre la capacidad lingüística y el origen de la lengua, 1795) Fichte rechaza explícitamente la noción hobbesiana de un estado originario (natural) de carácter belicoso: “¿Cómo se comporta, por el contrario, el ser humano originalmente con el mismo ser bumano?... ¿Deberían intentar dominarse entre ellos o, por el contrario, si no creen tener la fuerza suficiente para lograrlo, se escaparían mutuamente? [...] No obstante, vemos que los seres humanos se llevan bien entre sí, que se ayudan mutuamente y que mantienen relaciones sociales. La razón de este fenómeno tiene que estar en el ser humano mismo; en su original forma de ser tiene que poder mostrarse un principio que le determina de tal forma que se comporta con sus semejantes de otra manera que contra la naturaleza" ( GA I, 3: 99 - 100 / OL: 16 $-17)$ 
constituido, es decir, un individuo que ha despertado a la conciencia de su propia libertad y, por este motivo, es capaz de actuar para que el primero adquiera la suya. Esta diferencia inicial entre los miembros de la relación es lo que garantiza que los movimientos que ponen en marcha la interacción entre ellos no sean conflictivos. Puede decirse que tanto para Fichte como para Kierkegaard el modelo empírico a partir del cual se construyen los conceptos de Aufforderung e Indbydelse es el vínculo entre padres e hijos ${ }^{89}$.

2. El llamamiento a la libertad es un comportamiento de carácter atributivo: a través del requerimiento a la acción se le otorga al individuo el reconocimiento de una capacidad que aún no ha confirmado con su conducta. El exhortado, explica Fichte, "recibe el concepto de su actividad causal libre no como algo que es en el momento presente... sino como algo que debe ser en el futuro"..$^{0}$ Sin embargo, esta atribución que realiza el exhortante no es un juego experimental, no se trata de verificar o no la libertad del exhortado sino de influir positivamente sobre ella. ${ }^{91} \mathrm{El}$ exhortado no recibe su libertad de manos del exhortante; sin embargo, de no mediar la acción de este último - sin exhortación- el primero no accedería a la conciencia de su libertad:92 el exhortante supone la libertad en el exhortado para que éste la ponga en sí mismo y actúe en consecuencia. El pensamiento kierkegaardeano conserva este aspecto atributivo presente en Fichte pero lo reconfigura en función del concepto del "pecado original". 93 Pensado a

${ }^{89}$ La fidelidad a esta asimetría hace desembocar a Fichte en una tesis religiosa: los primeros hombres, en tanto que tales, no pudieron ser educados en su libertad por otros hombres, "por tanto, es necesario que los educara un ser racional distinto del hombre" (GA I, 3: 348 / FDN: 134).

${ }^{90}$ GA I, 3: $342-343$ / FDN: 129.

${ }^{91}$ En este punto, nos permitimos dejar sin determinar cuáles son los motivos por los cuales el exhortante se propone influir positivamente en el exhortado.

92 "El fundamento de la actividad causal del sujeto reside al mismo tiempo en el ser fuera de él y en él mismo... Si aquél no hubiera operado y con ello exhortado al sujeto a la actividad causal, éste mismo tampoco habría operado nunca" (GA I, 3: 349 / FDN: 135).

${ }^{93} \mathrm{Al}$ igual que Schelling, Kierkegaard considera que Fichte posee una comprensión disminuida del mal en la medida en que lo comprende como indolencia y pereza (véase SKS 1: 312 / CI: 299). 
partir de las coordenadas de la filosofía del danés, el esquema con el cual se maneja Fichte describe lo que en Philosophiske Smuler (Migajas Filosóficas, 1844) se denomina "magisterio socrático": el yo (discípulo) posee en sí mismo la condición de acceso a su libertad (verdad) y el trato con el otro (maestro) es solo el medio (ocasión) para alcanzarla. ${ }^{94}$ Sin embargo, el dogma cristiano del pecado establece que la falta de conciencia de la libertad no traduce una mera debilidad de la voluntad sino un estar en franca oposición a la libertad. Es necesario, por tanto, un "magisterio divino": la acción del otro (redentor) no sólo promueve la comprensión del yo como un agente libre sino que también otorga esta libertad (salva $)^{95}$.

3. Si el propósito final de la Aufforderung es la libre actividad causal de aquel a quien ésta se destina, debe decirse que a partir de ella es posible dejar atrás la asimetría inicial (influencia unidireccional) e instaurar un vínculo simétrico (influencia bidireccional) entre los individuos que interactúan entre sí. En el párrafo que antecede los corolarios del $₫ 3$ puede detectarse cierta modificación en el enfoque del texto, la exhortación que venía siendo analizada desde el punto de vista del exhortado, se piensa ahora desde la perspectiva del exhortante: "la causa de la influencia sobre nosotros no tiene otro fin sino que la conozcamos como tal". ${ }^{96}$ Este deslizamiento teórico se consuma en el $\S 4$ con la introducción de una categoría clave para la comprensión del vínculo intersubjetivo, el concepto de Anerkennung (reconocimiento). El reconocimiento, argumenta Fichte, no es una cuestión

\footnotetext{
94 Véase SKS 4: 218 - 222 / MF: $31-34$.

95 Véase SKS 4: 222 - 228 / MF: 34 - 39. Kierkegaard reproduce este mismo pensamiento en el primer discurso del Segundo volumen de Las obras del amor: "El amor edifica". La tarea del cristiano es promover en el otro el amor. Para ello, "el que ama presupone [forudsætter] que hay amor en el corazón de la otra, logrando cabalmente mediante este supuesto que el amor edifique en él a partir del fundamento" (SKS / LOA II: 24). El ser humano, por tanto, sólo puede presuponer y jamás poner el amor en el otro ya que esto último "es una relación impensable entre dos seres humanos y en este sentido es imposible que el amor humano sea edificante. Es Dios, el Creador, el que tiene que depositar el amor en cada hombre” (SKS 9: 219/ LOA II: 24).

${ }^{96}$ GA I, 3: 347 / FDN: 133.
} 
meramente intelectual, sino práctica. ${ }^{97}$ Reconocer al otro como un ser libre y racional significa comportarse en referencia a él de un modo específico: limitar la propia libertad por el concepto de la posibilidad de la libertad del otro..$^{98} \mathrm{La}$ acción concreta que le da expresión al reconocimiento es, paradójicamente, una acción inhibida, una auto-restricción (Selbstbeschränkung). La idea de fondo es que la libertad de un individuo se hace visible para sus semejantes a través del acto que traza un campo definido para su ejercicio. La libertad, por tanto, se hace visible en tanto y en cuanto afirma la libertad del otro: limitando voluntariamente su esfera de influencia deja al otro una esfera para su acción. El paso hacia el otro es un paso atrás. Reconocer propiamente esta libertad, responder afirmativamente a la interpelación inicial, implica un movimiento idéntico de auto-restricción:

La relación entre seres libres entre si es por eso la relación de una acción recíproca mediante la inteligencia y la libertad. Ninguno puede reconocer al otro si ambos no se reconocen recíprocamente; y ninguno puede tratar al otro como un ser libre si no se tratan así los dos recíprocamente. ${ }^{99}$

Ahora bien, para Fichte, la reciprocidad en el trato es una exigencia superior y común a la cual deben dar cumplimiento ambos participantes de la relación; ${ }^{100}$ por este motivo, el individuo sólo está obligado a tratar al otro como un ser libre en la medida en que aquel con quien se relaciona le dispense un trato similar. Así las cosas, cuando uno de los miembros no se

\footnotetext{
97 Véase GA I, 3: 352 / FDN: 138.

98 Véase GA I, 3: 358 / FDN: 144.

${ }^{99}$ GA I, 3: 351 / FDN: 137.

${ }^{100}$ Para desarrollar exitosamente su autonomía, el yo precisa no sólo ser reconocido por el otro sino también reconocerlo, es decir, que el reconocimiento sea recíproco. Dado que la exhortación que activa la libertad del yo es producto de la libertad del otro, el yo está, aunque no siempre tenga conciencia de ello, existencialmente interesado en la libertad del otro. Así lo expresa Fichte en su Sittenlehre de 1798: “mi impulso a la autonomía no puede, por tanto, en modo alguno dirigirse a aniquilar la condición de su propia posibilidad, es decir, la libertad del otro”. (GA I, 5: 201 / E: 257).
} 
comporta a la altura de este requerimiento, es decir, cuando no se comporta en relación a su semejante como un ser libre y racional, el otro miembro, amparado en la exigencia de reciprocidad, puede tratar al primero "como a un ser meramente sensible". ${ }^{101}$

Kierkegaard comparte la tesis de que la promoción de la libertad en el otro requiere un descentramiento práctico del yo, pero, en función de la orientación cristiana de su pensamiento, la radicaliza. Para Kierkegaard, lo hemos señalado en el punto anterior (2), en tanto y en cuanto el yo humano recurre exclusivamente a sus propias fuerzas es incapaz de despertar en el otro una libertad auténtica y ello en virtud del carácter finito de su libertad. Sólo una libertad infinita, como es la divina, tiene la potencia necesaria para contraerse a punto tal de hacer verdaderamente libre al otro. ${ }^{102}$ No obstante, este comportamiento de Dios hacia el hombre debe ser considerado la medida de la relación del yo con el otro. Según Las obras del amor lo que haría posible el repliegue del yo sobre sí mismo es la determinación del otro como "prójimo". El prójimo, dice el danés, debe estar tan próximo al yo como éste lo está de sí mismo "pues teniendo conciencia de ser dos, no hay posibilidad de ser un 'yo' en el sentido egoísta de la palabra". ${ }^{103}$ Cualquier otra comprensión del otro (incluso aquellas que lo califican como amante, amigo o compañero) implica, en última instancia, un comportamiento del yo que esconde una voluntad de dominio, el afán de proyectarse en el otro. ${ }^{104}$ Como hemos dicho, la tarea del yo en referencia al otro consiste en

\footnotetext{
101 GA I, 3: 356 / FDN: 142

102 Véase SKS 20: $57-58$.

103 SKS 9: 29 / LOA I: 69.

104 Véase SKS 9: 60 - 61 / LOA I: 118 - 119. En el \ 158 de su Filosofía del derecho, Hegel define el amor como el "ser sí mismo del yo en el otro" (véase Hegel G., Principios de la filosofía del derecho, trad. Vermal, Barcelona, Edhasa, 1999, p. 277 [Agr.]); pero es necesario notar que en el $\int 7$ tanto las experiencias del amor y la amistad como así también la mencionada fórmula que las definen describen el sentido más alto de la libertad (véase Ibid., p. 87[Agr.]). Kierkegaard, por su parte, complementaría esta fórmula añadiendo que tanto el amor como la libertad exigen el "ser sí mismo del otro en el yo".
} 
esforzarse por imitar ese movimiento divino de auto-negación de sí. ${ }^{105}$ Esa es la exigencia que el cristianismo le dirige a todo hombre. Dicha exigencia, explica Sergio Muñoz Fonnegra,

es unilateral porque ya no concierne a ambas partes de la relación, pues la exigencia recae sólo sobre el individuo... es radical porque va de la mano con una renuncia total a todo mérito, porque impele a amar sin esperar nada; la reciprocidad desaparece por completo de la relación... [es] una exigencia radical al individuo a trascender su egocentricidad. ${ }^{106}$

A diferencia de lo que ocurre en Fichte, el análisis de Kierkegaard no avanza desde la exhortación (Aufforderung) hacia el reconocimiento (Annerkerung) ${ }^{107}$. Las coordenadas que determinan su pensamiento parecerían no dejar lugar para una búsqueda conjunta de reconocimiento no egoísta. El trato entre individuos, si se quiere superar sus modalidades conflictivas, siempre debe replicar esa escena inicial forzosamente asimétrica.

Recibido: 01/2017; aceptado: 04/2017

105 "La plena adquisición de lo que Kierkegaard denomina libertad cristiana (christelige Friheden), exige una condición previa: el ejercicio de la abnegación, es decir, la negación de uno mismo, pero no en sentido ontológico de la expresión, sino en el sentido ético. La negación del yo no debe comprenderse como la descomposición de la identidad personal o la reducción nihilista de la mismidad, sino prioridad ética del prójimo" (Torralba Roselló F., Poética de la libertad. Lectura de Kierkegaard, Madrid, Caparrós Editores, 1998, p. 119).

106 Muñoz Fonnegra, Sergio, "La exigencia ética. Sobre la doctrina del amor de Kierkegaard", Estudios de Filosofía, No 32, (2005), p. 49.

107 "La pregunta es ahora, si yo reconozco la independencia del otro. Y esto no debe depender de si el otro me reconoce del mismo modo" (Grøn, Arne, "Reconocimiento y comunicación. La ética entre Hegel y Kierkegaard", p. 39). 